\title{
Adaptation of copper community tolerance levels after biofilm transplantation in an urban river
}

\author{
Lise C. Fechner $^{\mathrm{a}, \mathrm{b}, \text { * }}$, François Versace ${ }^{\mathrm{a}, \mathrm{b}}$, Catherine Gourlay-Francé ${ }^{\mathrm{a}, \mathrm{b}}$, \\ Marie-Hélène Tusseau-Vuillemin ${ }^{c}$
}

a Cemagref - Unité de Recherche Hydrosystèmes et Bioprocédés, 1 rue Pierre-Gilles de Gennes CS 10030 F-92761 Antony Cedex, France

${ }^{\mathrm{b}}$ FIRE, FR-3020, 4 place Jussieu, 75005 Paris, France

c IFREMER, Technopolis 40, 155 rue Jean-Jacques Rousseau, 92138 Issy-Les-Moulineaux, France

\author{
*: Corresponding author : Lise C. Fechner, Tel.: +3301409665 68 ; fax: +330140966199 ; \\ email address : lise.fechner@cemagref.fr
}

\begin{abstract}
:
The Water Framework Directive requires the development of biological tools which can act as earlywarning indicators of a sudden increase (accidental pollution) or decrease (recovery due to prevention) of the chemical status of aquatic systems. River biofilms, which respond quickly to modifications of environmental parameters and also play a key part in the functioning of aquatic ecosystems, are therefore good candidates to monitor an increase or a decrease of water pollution. In the present study, we investigated the biological response of biofilms transplanted either upstream (recovery) or downstream (deterioration of exposure levels) the urban area of Paris (France). Both modifications of $\mathrm{Cu}$ community tolerance levels and of global bacterial and eukaryotic community structure using automated ribosomal intergenic spacer analysis (ARISA) fingerprints were examined 15 and 30 days after the transplantation. Cu tolerance levels of the heterotrophic component of biofilms were assessed using a short-term toxicity test based on $\beta$-glucosidase (heterotrophic) activity. $\mathrm{Cu}$ tolerance increased for biofilms transplanted upstream to downstream Paris (5-fold increase on day 30) and conversely decreased for biofilms transplanted downstream to upstream (8-fold decrease on day 30). ARISA fingerprints revealed that bacterial and eukaryotic community structures of transplanted biofilms were closer to the structures of biofilms from the transplantation sites (or sites with similar contamination levels) than to biofilms from their sites of origin. Statistical analysis of the data confirmed that the key factor explaining biofilm Cu tolerance levels is the sampling site and not the site of origin. It also showed that $\mathrm{Cu}$ tolerance levels are related to the global urban contamination (both metals and nutrients). The study shows that biofilms adapt fast to modifications of their surroundings. In particular, community tolerance varies quickly and reflects the new exposure levels only 15 days after transplantation. Those results support the use of biofilms as reliable early-warning indicators of diffuse urban contamination.
\end{abstract}

\section{Highlights}

- Cu tolerance levels increase for biofilms transplanted upstream to downstream an urban area. $\mathrm{Cu}$ tolerance levels decrease for biofilms transplanted downstream to upstream an urban area. ARISA reveals modifications of community structures after transplantation. Biofilm tolerance is a sensitive biological response to diffuse urban pollution.

Keywords : River ; Biofilm ; PICT ; ARISA ; Urban contamination ; Transplantation 


\section{Introduction}

Over the past decades, human activities in urban areas have contributed to the increase of chemical contamination of aquatic ecosystems (Meybeck, 2003). In particular, urban areas are contaminated by mixtures of chemicals at low, sublethal concentrations (Tusseau-Vuillemin et al., 2007). It is essential to acquire knowledge on the response of aquatic organisms to such chemical contaminations in the field. The Water Framework Directive indeed requires improving both the ecological and the chemical status of aquatic systems before 2015. This consequently means that being able to monitor the biological response of aquatic organisms to a decrease or an increase of pollution levels is a key scientific challenge. It is also important to develop biological tools which can act as early-warning indicators of a deterioration of the chemical status of an aquatic ecosystem.

River biofilms are complex communities of both autotrophic and heterotrophic micro-organisms that develop in a matrix of exopolymers on submerged substrates such as pebbles, wood or sediment. They are typically composed of bacteria, micro-algae, fungi and protozoa. Because they are prompt to respond both structurally (for instance by changes in species composition) and functionally (for instance by changes in photosynthetic activity) to environmental disturbances, they are considered as early-warning indicators of chemical pollution (Sabater et al., 2007). Indeed, the short generation time of biofilm micro-organisms allows a rapid response to changing conditions. Moreover, biofilms play an important role in the functioning of aquatic ecosystems both as primary producers (autotrophic communities) and by taking part in the recycling of organic matter (heterotrophic communities). Biofilms are also an important source of food for a range of micro and macro benthic invertebrates and some fish (Burns and Ryder, 2001). Therefore, any modification in biofilms' structures and functioning can further alter the rest of the aquatic ecosystems.

Field transfer of periphytic communities between sites with different contamination levels appears as an efficient way to assess in situ effects of chemical contamination. Several authors have investigated changes in diatom species composition (Gold et al., 2002; Morin et al., 2010; Rimet et al., 2005; Rotter et al., 2011), algal community structure (Dorigo et al., 2010a) and algal (Dorigo et al., 2010a; Rotter et al., 2011) or heterotrophic community tolerance (Tlili et al., 2011) after transplantation between polluted and uncontaminated sites. Yet information on the responses of natural biofilms to sudden stress or stress removal, for instance after transplantation, is still scarce (Dorigo et al., 2010b; Rotter et al., 2011), although it might help better understand the link between toxic pressure and biological responses at the community level. 
Moreover, little information is usually available on the response of the heterotrophic component of biofilms in case of transplantation or sudden modification of water contamination. Yet aquatic heterotrophic communities might be good indicators of chemical contamination. For instance, Paule et al. (2009) have observed that the bacterial community structure of biofilms was clearly modified by transplantation showing that site characteristics condition the structure of microbial communities. Therefore, heterotrophic communities are likely to respond fast to changes of exposure parameters. However, most studies on biofilms have focused on photosynthetic microorganisms although some studies have included data on bacterial communities in the last 10 years (Burns and Ryder, 2001; Dorigo et al., 2010b; Tlili et al., 2011).

Exposure of biofilms to a toxicant leads to the disappearance of sensitive components (species, genotypes and phenotypes) which are gradually replaced by more tolerant ones (Blanck, 2002). These selection, adaptation and acclimatation processes are at the basis of the PICT (PollutionInduced Community Tolerance) approach as they lead to an increase of the global community tolerance (Blanck et al., 1988). As a community approach, PICT provides relevant ecological information regarding biological responses to chemical contaminations. Indeed, effects measured at the community level include interactions between assemblages of various populations and integrate variations in terms of sensitivity between community organisms (McClellan et al., 2008). Community tolerance is assessed by the use of short-term toxicity tests based on the inhibition of physiological activities (typically photosynthesis to evaluate the tolerance of autotrophic communities as discussed by Bérard et al. (2002)). A new short-term toxicity test has recently been developed using $\beta$-glucosidase activity as an endpoint (Fechner et al., 2010a). It proved to be efficient to detect tolerance acquisition of the heterotrophic component of metal-exposed periphyton (Fechner et al., 2011b). Tlili et al. (2010) also used beta-glucosidase activity to study pesticide-tolerance acquisition of biofilms exposed in microcosms.

The aim of this study was to evaluate the dynamics of metal tolerance of biofilms transplanted either upstream or downstream an urban area (Paris, North of France). The potential to either recover from (communities transplanted upstream) or adapt to (communities transplanted downstream) urban stress was investigated both in terms of heterotrophic community tolerance (using $\beta$-glucosidase activity) and global community structure. Copper was chosen as one of the major metals present in the mixture of contaminants in the river (Fechner et al., 2011a). Biofilms transplanted upstream to downstream the urban area were expected to acquire tolerance to copper and inversely, communities transplanted downstream to upstream were expected to either maintain or lose their relatively high tolerance levels. ARISA (Automated Ribosomal Intergenic 
Spacer Analysis) fingerprinting was chosen to visualize similarities between bacterial and eukaryotic community structures of both transplanted and original biofilms.

\section{Materials and Methods}

\subsection{Sampling sites and water chemistry}

Periphytic communities were collected (and/or transplanted see below in 2.2) on three sites located in the Seine river basin (North of France): site A (Marnay), which is located upstream from the urban area of Paris in the Seine river, site B1 (Saint-Maurice) which is located in the urban area of Paris, upstream from Paris in the Marne river and $170 \mathrm{~km}$ downstream from site A, and site B2 (Triel) which is located in the Seine river downstream from Paris and the sewer treatment plant Seine-Aval (which receives most of Paris wastewater, nominal capacity $810^{6}$ inhabitants) and $90 \mathrm{~km}$ downstream from site B1. The urban area of Paris is characterized by intense human activity which explains the diffuse urban contamination gradient (increase of metals, nutrients and organic pollutants) upstream to downstream the Seine river basin (Priadi et al., 2011). Physico-chemical parameters of the river water (concentrations of $\mathrm{HCO}_{3}^{-}, \mathrm{Na}^{+}, \mathrm{K}^{+}$, $\mathrm{Mg}^{2+}, \mathrm{Ca}^{2+}, \mathrm{Cl}^{-}, \mathrm{SO}_{4}^{2-}, \mathrm{NH}_{4}^{+}, \mathrm{NO}_{2}{ }^{-}, \mathrm{PO}_{4}^{3-}, \mathrm{NO}_{3}^{-}$and $\mathrm{SiO}_{2}$ ) were measured on day 0,15 and 30 at sites A, B1 and B2 (August 2009). Mean total and dissolved metal concentrations (Cu, Cd, Ni, $\mathrm{Zn}, \mathrm{Pb}, \mathrm{Cr}, \mathrm{Co} \mathrm{Mn}$ ) were obtained with several individual samplings over the period corresponding to the transplantation experiment (samplings on $22^{\text {nd }}$ July, $19^{\text {th }}$ August and $29^{\text {th }}$ September 2009) at sites A and B2. DGT-labile metal concentrations were measured after a onemonth immersion of three DGT devices at the sampling sites. As regards site B1, metal concentrations (total, dissolved and labile) were measured before (21 $1^{\text {st }}$ January 2009) and after $\left(22^{\text {nd }}\right.$ September 2009) the experiment: a mean value of each metal concentration was thus used to characterize metal contamination at site B1.

\subsection{Biofilm transplantation and sampling}

Biofilms were collected on Low Density PolyEthylene (LDPE) plastic membranes $\left(30 \times 10 \mathrm{~cm}^{2}\right)$ that were vertically attached to plastic crates as in Fechner et al. (2010a). For transplantation, communities were collected at sites B1 and A (after 23 and 34 days of colonization respectively). At the beginning of the experiment (day 0), 5 colonized-LDPE membranes were collected at site A, immersed in a clean plastic container (previously washed with $10 \% \mathrm{HNO}_{3}$ ) filled with river 
water and transported in a cooler, and were taken to site B2 where they were attached to another plastic crate and immersed in the river (Figure 1). Inversely, 5 biofilm-colonized LDPE membranes were collected at site B1 and transported to site A (day 1). 5 other biofilm-colonized membranes were left at both sites. Transplanted communities will thereafter be called TA (transplanted from A to B2), and TB1 (transplanted from B1 to A); communities collected on sites A and B1 will be called A and B1. After 15 and then 30 days of transplantation (day 15 and 30), biofilms were collected at sites A, B1 and B2 (both transplanted and original communities). After collection, plastic membranes were transported back to the laboratory in $250 \mathrm{~mL}$ glassbottles placed in a cooler within the day. They were then hand-scraped to remove periphyton and make biofilm suspensions in Montdore (Grand Barbier, Mont-Dore, France) mineral water (Fechner et al., 2010a). Aliquots of the suspensions were then assigned to various analyses for periphyton characterization or tolerance measurements.

\subsection{Biofilm characterization}

For each biofilm sample, biofilms' dry weights (DWs), ash-free dry weights (AFDWs), and chlorophyll $a$ (Chl a) concentrations were measured as in Fechner et al. (2010b). To obtain bacterial and eukaryotic ARISA fingerprints of the communities, triplicates of aliquots $(50 \mathrm{~mL})$ of biofilm suspensions were centrifuged for 15 minutes at $10000 \mathrm{~g}$ and $4^{\circ} \mathrm{C}$. Supernatants were discarded and pellets were frozen and stored at $-80^{\circ} \mathrm{C}$ for further use.

\subsection{ARIS A fingerprinting of biofilms}

ARISA is a fast and efficient technique to detect global genetic changes in eukaryotic and bacterial community structures of complex, environmental communities. Both eukaryotic and bacterial ARISA were performed on biofilm samples collected on day 15 and 30 (in triplicates) as in Fechner et al. (2010b). Briefly, DNA was extracted from biofilm pellets using the Power Soil DNA Isolation Kit (Mobio Laboratories, Inc., Carlsbad, US). Amplification of bacterial 16S-23S ITS was performed by PCR using primers ITSF/ITSReub (Cardinale et al., 2004) and primers 2234C/3126T (Ranjard et al., 2001) were used to perform amplification of eukaryotic ITS1-5.8SITS2 regions of fungal and algal species (Fechner et al. 2010b). Amplicons were separated on an electrophoresis Bioanalyzer (2100 Electrophoresis Bioanalyzer, Agilent Technologies, Santa Clara, CA) and fluorescence data was converted into electrophoregrams using 2100 Expert software (Agilent Technologies, Santa Clara, CA, US). Electrophoregrams in ASCII formats were 
imported into the StatFingerprints R package (Michelland et al., 2009) and processed as in Fechner et al. (2010b).

\subsection{Cu community tolerance}

Copper tolerance of the heterotrophic communities was measured using the normalized $\mathrm{EC}_{50}$ values obtained with the short-term toxicity test based on $\beta$-glucosidase measurements (Fechner et al., 2011b; Fechner et al., 2010a). Briefly, biofilms were exposed for one hour to acute levels of metals (at least six concentrations of metal varying between 0.001 and $10 \mathrm{mM}$ were tested in triplicates for each toxicity test). Metal exposure levels during the toxicity tests were checked by measuring metal concentrations in the stock solutions by flame AAS (Varian Inc., USA). Fluorescence measurements were converted into MUF concentrations by calibrating the spectrofluorimeter with a range of MUF solutions prepared in demineralised water. \% inhibition of $\beta$-glucosidase activity was then calculated using MUF concentrations measured for each metal concentration tested.

Community tolerance to $\mathrm{Cu}$ was assessed by calculation of a normalized $\mathrm{EC}_{50}$ value by dividing the $\mathrm{EC}_{50}$ value (obtained from the dose/effect curve, see 2.6) by the Total Suspended Solids (TSS) concentration of the periphyton suspension used for the short-term test (Fechner et al., 2010a). TSS-normalized $\mathrm{EC}_{50}$ values provide a reliable and robust estimation of metal tolerance and do not depend on experimental conditions. $\mathrm{Cu}$ tolerance levels were measured on the biofilms collected at sites A and B1 on day 0, 15 and 30 and also on transplanted communities TA and TB1 on day 15 and 30.

\subsection{Statistical analysis}

For each toxicity test, $50 \%$ effect concentrations $\left(\mathrm{EC}_{50}\right)$ and maximum inhibition levels were determined from the dose/effect curve, which was obtained by plotting the $\%$ inhibition of $\beta$ glucosidase activity as a function of metal concentration, and by fitting the data to the Hill model (Hill, 1910; Vindimian, 2001). The general form of the curve fitted on the data is:

$$
F(x)=\% \max \times \frac{x^{H}}{x^{H}+E C_{50}{ }^{H}}
$$

where $\mathrm{x}$ is the metal concentration, \%max is the predicted effect when the toxicant concentration is infinite, and $\mathrm{H}$ is the Hill number (slope of the toxicity curve). Each parameter (\%max, $\mathrm{EC}_{50}$ and $\mathrm{H}$ ) was adjusted for the calculation by non-linear regression. 95\% confidence intervals around the fitted parameters were estimated using a Bootstrap method. Parameters $\left(\mathrm{EC}_{50}\right.$ values 
and maximum $\%$ inhibition) were considered significantly different when $95 \%$ confidence intervals were disjointed.

The effects of metal contamination on river biofilms' tolerance levels and descriptors (DW, AFDW and Chl a) was further examined using Partial Least Squares (PLS) regression. PLS is a regression extension of PCA which is used to connect two blocks of variables (X and Y) to each other. It derives its usefulness from its ability to analyze data with noisy, collinear or even incomplete variables. Moreover, the precision of the PLS model increases with the number of X variables (Eriksson et al., 2006). In the present study, PLS regression was performed with $\mathrm{Cu}$ tolerance and biofilm descriptors as the $\mathrm{Y}$ variables and the environmental parameters of the river water (both physico-chemical parameters and metal concentrations) as the X-variables. The quality of a PLS regression model can be assessed both in terms of goodness of fit (it is possible to compute the explained variances of both $\mathrm{X}$ and $\mathrm{Y}$-variables by calculating $\mathrm{R}^{2} \mathrm{X}$ and $\mathrm{R}^{2} \mathrm{Y}$ ) and goodness of prediction $\left(\mathrm{Q}^{2}\right)$ which is evaluated by cross-validation. The importance of each $\mathrm{X}$ variable in the regression model can be summarized by its Variable Influence in the Projection (VIP) value, which takes into account the amount of explained Y-variance and may be used to discriminate between X-variables. PLS regression was performed using XLStat 2010 (Addinsoft, France). Before the PLS regression, all the data was log-transformed and normalized.

Principal Component Analysis (PCA) was performed on the ARISA profiles (electrophoregrams) to visualize similarities between community profiles. Euclidian distances between fingerprints were also computed and analysis of similarity (ANOSIM) was performed on the Euclidian distance matrix (1000 permutations) to test the effect of several parameters: sampling date (day 15 or day 30), site of origin (either A or B1) and sampling site (either upstream for communities $\mathrm{A}$ and TB1 or downstream for communities TA and B1) on bacterial and eukaryotic ARISA profiles. ANOSIM is a non-parametric permutation procedure which tests whether differences in dissimilarity between groups exceed differences within groups. It generates a global test statistic (R) which varies between -1 and 1 and which magnitude indicates the degree of separation between groups of samples. A value of 1 indicates complete separation whereas a value of 0 indicates no separation. PCA and ANOSIM were performed using StatFingerprints. 


\section{Results}

\subsection{Environmental parameters at the study sites}

Mean physico-chemical parameters of the river water at the three sites (Table 1) correspond to annual means reported elsewhere (Priadi et al., 2011). Except for $\mathrm{HCO}_{3}^{-}$which tends to remain constant at all sites, most parameters tend to increase upstream to downstream the Seine river basin $\left(\mathrm{NO}_{3}^{-}, \mathrm{PO}_{4}^{3-}, \mathrm{SiO}_{2}, \mathrm{Na}^{+}, \mathrm{K}^{+}, \mathrm{Mg}^{2+}, \mathrm{Ca}^{2+}, \mathrm{Cl}^{-}, \mathrm{SO}_{4}^{2-}, \mathrm{SiO}_{2}\right)$.

Metal concentrations (Figure 2) were always higher at the downstream sites (B1 and B2) than at site A by a factor ranging from 1.7 (dissolved Co) to 16.4 (labile Mn). Cu levels increased by a factor 3 (total) to 5 (labile) from site A to site B2 and decreased by a factor 2 (labile) to 5 (total) from site B1 to site A. Although sites B1 and B2 are located in different areas (in particular site B1 is located upstream from Paris and site B2 downstream from Paris), differences between both downstream sites were not significant for the great majority of metals considering the standard deviations which represent the temporal variability of exposure levels. Figure 2 also reveals that dissolved metal concentrations of $\mathrm{Cd}, \mathrm{Ni}$ and $\mathrm{Pb}$ remain much lower than the Environmental Quality Standards (EQSs) of the European WaterFramework Directive while $\mathrm{Cu}$ and $\mathrm{Zn}$ are within the range of the EQSs. Dissolved Cu concentrations reach EQS levels at site B2.

\subsection{General biofilm descriptors}

Biofilm descriptors tend to vary from one sampling date to another (Table 2) which makes comparison between biofilm samples complex based on these parameters. DW and AFDW tend to be higher at site B1 when compared to site A except on day 15, whereas $\mathrm{Chl} a$ is always higher at site B1. The biofilm transplanted to site B2 (TA) had lower DW and AFDW than the biofilm from site A, but a higher Chl a concentration. The biofilm transplanted to site A (TB1) had lower $\mathrm{Chl} a$ values when compared to the site $\mathrm{B} 1 \mathrm{biofilm}$ but higher $\mathrm{Chl} a$ values when compared to the non-transplanted site A biofilm.

\subsection{Cu community tolerance levels}

A clear effect of transplantation was observed on community tolerance to $\mathrm{Cu}$ with the $\beta$ glucosidase toxicity test. Normalized $\mathrm{EC}_{50}$ values of transplanted communities increased by a factor 5 (day 30) to 22 (day 15) when comparing A and TA communities whereas they decreased by a factor 6 (day 15) to 8 (day 30) when comparing B1 and TB1 communities (Figure 3). 
Therefore transplantation of an upstream biofilm to a downstream site leads to a higher $\mathrm{Cu}$ tolerance after 15 days, whereas transplantation of a downstream community to an upstream site leads to a loss of $\mathrm{Cu}$ tolerance for the transplanted community after 15 day. These effects are maintained a month after the transplantation (day 30).

\subsection{PLS regression}

A four-component PLS regression model was produced with a good fit (96 and 95\% of explained variance for the $\mathrm{Y}$ and $\mathrm{X}$ variables respectively) and with good predictive ability $\left(\mathrm{Q}^{2}=0.76\right.$, data not shown). As the cumulated goodness of prediction $\mathrm{Q}^{2}$ was superior to 0.5 considering only the first two components, which is considered good (Eriksson et al., 2006), PLS regression was performed again allowing only two components for the regression model (Table 3) for an easier interpretation of the results. The two-component model was good with a $\mathrm{Q}^{2}$ of 0.58 and 88 and $80 \%$ of explained variance for the $\mathrm{Y}$ and $\mathrm{X}$ variables respectively. The variables with the greatest influence (VIP > 1) in the model are nitrites, phosphates, $\mathrm{HCO}_{3}^{-}$, labile and dissolved $\mathrm{Cr}$ and labile $\mathrm{Pb}$ (Table 4). The correlation circle (Figure 4) reveals that communities (biofilms A, TA, B1 and TB1 on day 0,15 and 30) are plotted along the first axis (first component t1) along the contamination gradient (metal concentrations are positively correlated with t1) and according to their sampling sites and not to their sites of origin (for the transplanted communities). 


\subsection{ARIS A fingerprinting of transplanted communities}

PCA analysis of ARISA fingerprints revealed interesting patterns in both bacterial and eukaryotic profiles (Figure 5). For bacterial ARISA, the first two principal components accounted for 54.25 $\%$ of the total variance and for eukaryotic ARISA, they accounted for $63.04 \%$. Communities collected on site A (both A and TB1) were grouped on the left of the graph whereas communities collected downstream (B1 and TA) were grouped on the right of the graph for bacterial ARISA. Similarly, upstream and downstream communities were separated along the first axis for eukaryotic ARISA. ANOSIM confirmed the importance of the sampling site (Global R $=0.31, \mathrm{p}$ $<2.210^{-16}$ and $0.43, \mathrm{p}<2.210^{-16}$ for bacterial and eukaryotic ARISA respectively) and the lack of influence of the site of origin on community structure (Global $\mathrm{R}=0.09, \mathrm{p}=0.045$ and $0.16, \mathrm{p}=$ 0.01 for bacterial and eukaryotic ARISA respectively). A significant impact of the sampling date was observed on bacterial ARISA profiles (Global $\mathrm{R}=0.45, \mathrm{p}<2.210^{-16}$ ) but not on eukaryotic profiles (Global $\mathrm{R}=0.12, \mathrm{p}=0.037)$.

\section{Discussion}

\subsection{Environmental factors related to Cu tolerance of fluvial biofilms}

The study aimed at linking urban exposure to biological effects in fluvial biofilms. The short-term toxicity tests showed that both transplanted and non-transplanted communities collected downstream from the Paris area were significantly more tolerant to $\mathrm{Cu}$ than communities collected upstream (either transplanted or not). Moreover, measurements of environmental parameters (both metal contamination levels and physico-chemical parameters) showed that urban contamination is significantly higher downstream from the urban area of Paris. Therefore, the study shows that community tolerance to $\mathrm{Cu}$ and urban exposure levels are clearly correlated. The PLS regression was used as a means to explore further the relationships between $\mathrm{Cu}$ tolerance levels and all the environmental variables likely to modulate community tolerance. Indeed, an increase of community tolerance is related to selection and adaptation phenomenons within the exposed community leading to the disappearance of sensitive species, genotypes or phenotypes. However, the species composition is also influenced by natural variations of environmental parameters (Bérard et al., 1999; Fechner et al., 2010b). As community tolerance integrates the different sensitivities (to a given toxicant) of species present in the community, natural modifications of species composition (as opposed to toxicant-induced variations) might 
also modify community tolerance as observed for instance for phytoplankton exposed to atrazine (Bérard and Benninghoff, 2001).

In the present study, PLS suggests that both metal pollution and water chemistry influence $\mathrm{Cu}$ tolerance levels. Factors like nutrients, for instance phosphates which appear among the most influential parameters in the regression model with a VIP $>1$, and metal concentrations, especially $\mathrm{Cr}$ and $\mathrm{Pb}(\mathrm{VIP}>1)$, are correlated to $\mathrm{Cu}$ tolerance. Nutrients have indeed been shown to modify tolerance patterns in periphyton (Serra et al., 2010; Tlili et al., 2010) especially for heterotrophic communities (Tlili et al., 2011). As regards the influence of metals other than $\mathrm{Cu}$ on $\mathrm{Cu}$ community tolerance, co-tolerance to several metals has already been brought to light for periphytic algae (Soldo and Behra, 2000), and even on the heterotrophic component of periphyton with the toxicity test used in the present study (Fechner et al., 2011b). For microorganisms, co-tolerance can be related to intra or extracellular immobilization of metal ions. As far as biofilms are concerned, extracellular biosorption of metals by ExoPolysaccharides (EPS) from the matrix is a well-known mechanism ( $\mathrm{Vu}$ et al., 2009). In that case, the tolerance mechanism is not specific to a given metal. Other tolerance mechanisms include metal efflux or decrease of metal uptake by modification of channel or carrier proteins used by the metal ions to enter the cells (Harrison et al., 2007; Kučera et al., 2008). Those mechanisms are usually more specific to one metal or a small group of metals. For instance, co-tolerance to $\mathrm{Zn}$ and $\mathrm{Cu}$ has been observed in several studies on periphytic algae (Gustavson and Wängberg, 1995; Soldo and Behra, 2000) thus indicating similar modes of action or detoxification for both metals. It is therefore not surprising to find metals other than $\mathrm{Cu}$ among the most influential parameters in the regression model. However, as biofilms are complex communities composed of different micro-organisms which differ in their susceptibility to metals and tolerance mechanisms, it is difficult to link $\mathrm{Cu}$ tolerance to exposure to a specific metal, all the more so as urban rivers are multi-contaminated. The PLS regression suggests that $\mathrm{Cu}$ tolerance has to be related to the global urban exposure as numerous metals appear among the most influential variables in the model. Moreover, the great majority of environmental parameters are tightly correlated as revealed by Figure 4 and by the great number of parameters with significant VIPs $(>0.8)$. Therefore, precise identification of the influence of co-varying parameters on $\mathrm{Cu}$ tolerance levels is difficult. $\mathrm{Cu}$ tolerance levels are thus related to the global urban exposure parameters (both micro-pollutants and nutrients). 


\subsection{Importance of tolerance measurements to assess the impact of diffuse urban pollution}

The study reveals that classical biofilm descriptors such as DW, AFDW and Chl $a$ are not as closely related to metal exposure as metal tolerance measurements, which confirms a similar observation in another field study in the Seine river basin (Fechner et al., 2011a). It is possible that other environmental factors such as light or water velocity exerted a predominant influence on those parameters, as both structure and function of periphyton have proved to be affected by variations of light and hydrodynamics of their growth system (Villeneuve et al., 2009). Classical biofilm descriptors have been commonly used as descriptors of biofilm biomass and may sometimes express the long-term effects of toxicants or water chemistry on periphytic communities (Burns and Ryder, 2001; Sabater et al., 2007). Yet they are not always clearly influenced by water chemistry and are thus not considered as reliable indicators of water quality (Montuelle et al., 2010). The present study thus confirms that those classical biofilm descriptors are not clearly influenced by diffuse urban contamination and should not be used as indicators of such pollution.

Tolerance measurements appear as particularly sensitive indicators of diffuse multi-metallic exposures, all the more so as metallic exposure levels are low in the present study. For instance, Gold et al. (2002) observed modifications of diatom density and taxonomic composition two weeks after transferring periphyton from a reference site to a polluted site, but exposure levels were approximately 100 higher $(12 \mu \mathrm{g} / \mathrm{L} \mathrm{Cd}$ and $640 \mu \mathrm{g} / \mathrm{L}$ dissolved $\mathrm{Zn}$ compared to respectively 0.01 and $5.1 \mu \mathrm{g} / \mathrm{L}$ at site $\mathrm{B} 2$ during the experiment). Metal contamination levels considered individually are either lower or within the range of quality standards (for instance the EQSs from the European Water Framework Directive). This observation is interesting as environmental quality standards are designed to be able to discriminate between a "good" or "bad" chemical status at a given sampling site. Using biological responses measured at the community level, it is thus possible to observe adverse effects due to urban contamination on sites that might be considered in a good chemical state depending on the chemicals considered. Other studies have reported adverse effects at the community level for exposure concentrations that are currently considered as protective using risk assessments procedures (Lewis, 1992; McClellan et al., 2008). Indeed, current regulations rely mostly on extrapolation of data obtained with single-species toxicity tests. Therefore, neither mixture effects nor the complexity of species interactions in the field are taken into account. The present study confirms that community-level biological responses might be a good alternative to single-species toxicity testing for environmental risk assessment, for instance using periphyton and a PICT approach. 


\subsection{Biofilm origin is a less important structuring factor than the sampling site}

Only 15 days after the transplantation, $\mathrm{Cu}$ tolerance (expressed as normalized $\mathrm{EC}_{50}$ values) of the TA biofilm (transplanted to site B2) reached levels comparable to those reported for periphyton collected at site B2 a month earlier in a previous study (Fechner et al., 2011a). Similarly, the tolerance level of the TB1 community, transplanted to site A, was similar to the tolerance level corresponding to periphyton from site A (Figure 3a). Moreover, PCA analysis of ARISA profiles revealed that both bacterial and eukaryotic profiles are discriminated by the sampling site and not by the site of origin of biofilm samples. Therefore, transplantation has a predominant impact on periphyton both in terms of community structure and tolerance levels. Those results are confirmed by the PLS regression model which allows to discriminate biofilm samples according to their sampling sites notwithstanding their sites origin.

\subsection{Fast modifications of periphytic communities after transplantation}

Recovery of low tolerance levels (for downstream communities transplanted upstream) and tolerance acquisition (for upstream communities transplanted downstream) was particularly fast as 15 days were sufficient to observe drastic changes in heterotrophic tolerance levels. Dorigo et al. (2010a) also observed a fast recovery of periphyton transferred from a site contaminated with diuron to a reference site. Autotrophic biofilm tolerance $\left(\mathrm{EC}_{50}\right)$ to diuron had significantly decreased and reached a level comparable to the tolerance level of periphyton from the reference site one week after the transplantation. This is close to what was observed in the present study in an urban context and focusing on heterotrophic biofilms. Moreover, Dorigo et al. (2010a) obtained 18S-DGGE fingerprints indicating a total recovery of the algal community structure 5 weeks after transplantation but remaining differences from the non-transplanted community 1 and 3 weeks after transplantation. This observation is also close to the results obtained with ARISA fingerprints in the present study. Indeed, ARISA revealed that modifications in community tolerance were accompanied by significant modifications of community structure in transplanted biofilms: the fingerprints of transplanted communities are clearly more similar to the fingerprints of non-transplanted communities collected at the site of transplantation (TB1 and A biofilms) or at a similarly-contaminated site (TA and B1 biofilms). It therefore seems that transplantation induces succession processes that are probably related to the increase or decrease of community tolerance levels after transplantation. Furthermore, both recovery and tolerance acquisition occurred at the same pace. Those conclusions are also similar to the observations made by Paule et al. (2009) using 16S-DGGE to investigate modifications in biofilms 
transplanted between an agricultural and a forested watershed basins. Indeed, they observed a significant influence of transplantation after 2.5 weeks on the structure of bacterial communities. In the present study, ARISA fingerprints also suggest that eukaryotic community structures remain different between transplanted and non-transplanted communities from the same sampling site even 30 days after transplantation, especially TA and B1 communities.

Rimet et al. (2005) also report differences between transferred and non-transferred diatom assemblages 40 to 60 days after a transplantation from polluted sites to a reference site. It is therefore possible that a closer taxonomic review of diatom species would have revealed further differences between transplanted and non-transplanted communities with similar ARISA fingerprints (A and TB1 communities in particular). Yet, ARISA remains sensitive enough to distinguish communities collected at different sites and to detect modifications in community structure in field communities over 15 days (site A and B1 non-transplanted communities collected on day 15 and on day 30 of the experiment).

The rapidity of structural modifications and $\mathrm{Cu}$ tolerance levels raises questions about the nature of transplanted biofilms. Indeed, it is always possible to observe a major sloughing of colonized substrata after transplantation, followed by re-colonization of the surfaces by a new community, similar to the native biofilms at the site of transplantation. The dynamics of biofilm growth is a complex mechanism reflecting the influence of physical, chemical and biological factors. Processes like sloughing (Bouletreau et al., 2006) or grazing may lead to sudden and drastic loss of biomass and might occur on transplantated communities for which environmental surroundings are abruptly changed. It is unlikely that biomass detachment occurred in the present study: for the TB1 biofilm (transplanted to site A), Chl a levels decreased but remained higher than levels registered for the local A community. As regards the TA biofilm transferred downstream from Paris (site B2), a decrease of DW was observed at day 15 and maintained at day 30 but the values registered corresponded to DW levels obtained on biofilms from the site of transposition (B2), collected in another study during the same period (Fechner et al., 2011a). Moreover, both AFDW and Chl a levels increased when compared to the original biofilm (biofilm from site A on day 0), and algal biomass was much higher for the TA biofilm than for the A biofilm on both day 15 and 30. Therefore, it is not likely that transplanted communities suffered major losses of biomass and were almost totally replaced by new communities following transplantation. Yet, constant import and export of planktonic species occur in biofilm rivers (Sigee, 2005) and are likely to have contributed to a fast recovery/adaptation of transferred communities. 
The fast modification of both tolerance level and community structure of transplanted biofilms is also probably related to the colonization time and substrata. Indeed, Dorigo et al. (2010b) did not observe recovery (in terms of tolerance levels and community structure) for biofilms collected on stones that were transplanted from a contaminated area to a clean site in contrast to the results that were discussed above, in which they observed almost total recovery for biofilms that were transplanted in a similar experiment but after colonization on artificial substrates (Dorigo et al., 2010a). They hypothesized that immigration of local organism in the transplanted communities was probably more difficult in the mature biofilms grown on river rocks. In the present study, the use of plastic membranes to grow biofilms might thus have positively influenced the speed of modifications of both community structure and tolerance.

\section{Conclusion}

In conclusion, the transplantation experiment revealed that both biofilm metal tolerance levels and the structure of bacterial and eukaryotic communities were markedly impacted by transplantation i.e. by a sudden modification of the environmental parameters. PLS allowed to discriminate upstream and downstream communities in a global multi-linear regression model which takes into account all the environmental parameters (physico-chemical and metal exposure levels) with good fitting parameters. Those results thus confirm that tolerance is a fast, earlywarning indicator of diffuse multi-metallic urban contamination at low exposure levels.

\section{Acknowledgements}

This study was supported by ONEMA and is part of the SISTEO project from the Ile-de-France Regional Council. The authors would like to thank Aurélie Germain for her valuable help both in the field and laboratory, and Julien Guieu for editing the English version of the manuscript. 
Figure 1. Map of the Seine river basin showing the three sites A, B1 and B2. Arrows materialize the transplantation of biofilms from site A to site B2 on day 0 of the experiment, and from site B1 to site A on day 1.

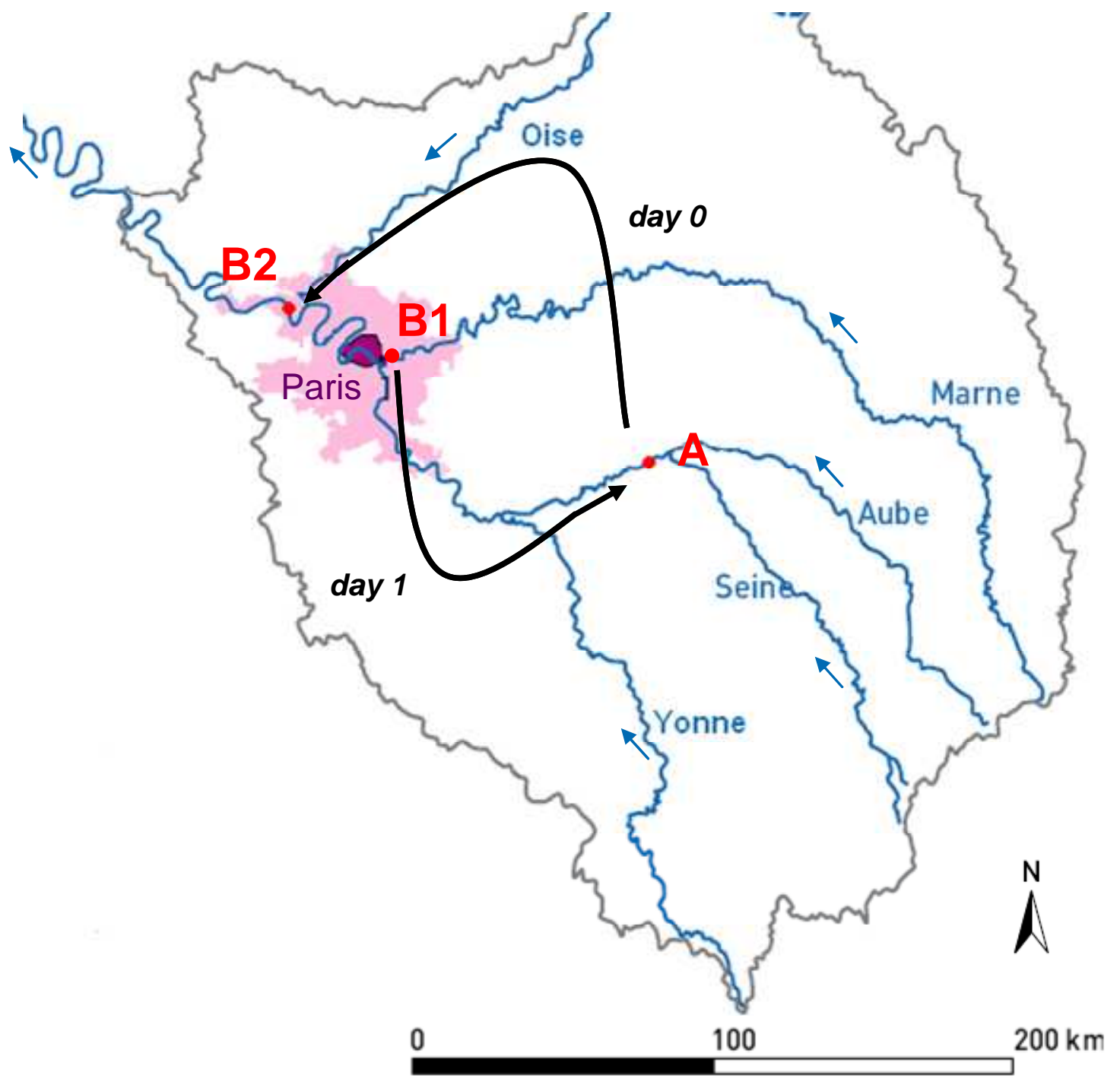


Figure 2. Histograms of mean total (a), dissolved (b) and labile (c) metal concentrations at the three sites A, B1 and B2 ( $\mathrm{n}=3$, corresponding to three samples in July, August and September 2009 for sites A and B2 ; $\mathrm{n}=6$, corresponding to two sets of three samplings in January and September 2009 for site B1). Error bars show standard deviations $( \pm \sigma)$. The labile metal concentrations were calculated using sets of three DGTs immersed at each site for one month. Multiplying factors were applied to $\mathrm{Cd}, \mathrm{Zn}$ and $\mathrm{Mn}$ concentrations for more clarity and are indicated below each histogram. EQSs (dissolved metal concentration in $\mu \mathrm{g} / \mathrm{L}$ ) from the European Water Framework Directive are indicated in histogram b (using the same multiplying factors e.g. 1.5 for $\mathrm{Zn}$ ). EQSs for $\mathrm{Ni}, \mathrm{Pb}$ and $\mathrm{Cd}$ (respectively 20, 7.2 and 5 with the multiplying factor of 20 for $\mathrm{Cd}$ ) are outside of the graph.

$\mathbf{a}$

Total metals $(\mu \mathrm{g} / \mathrm{L})$

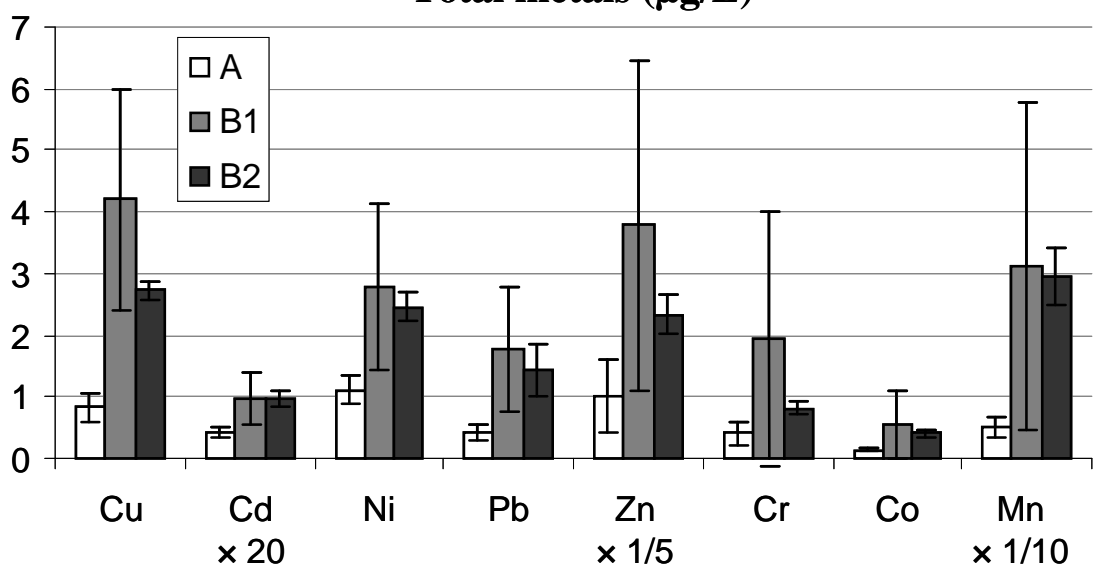

b

Dissolved metals $(\mu \mathrm{g} / \mathrm{L})$

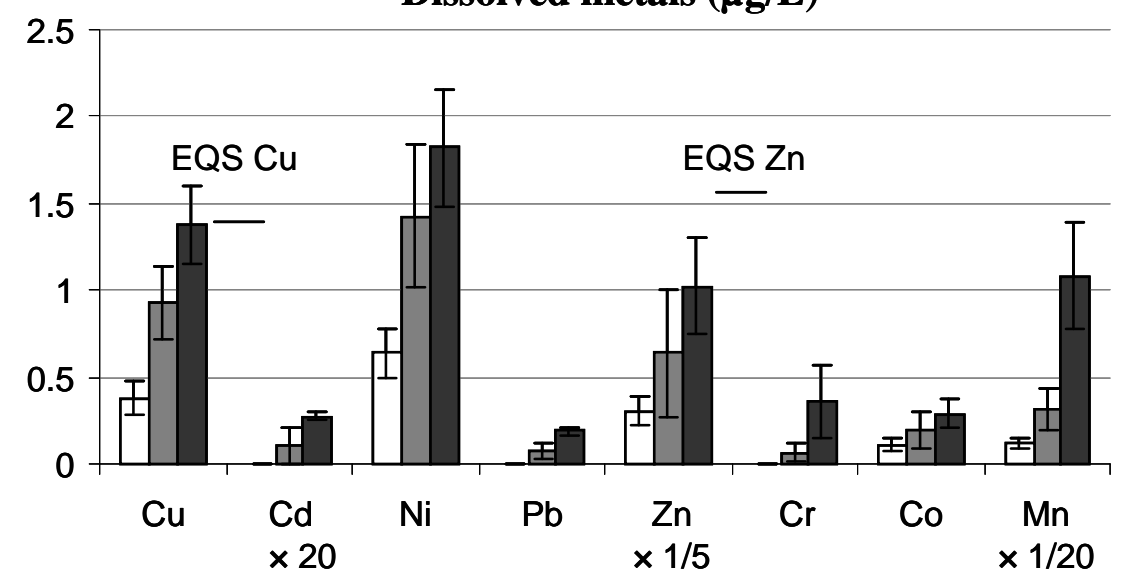

c

Labile metals $(\mu \mathrm{g} / \mathrm{L})$

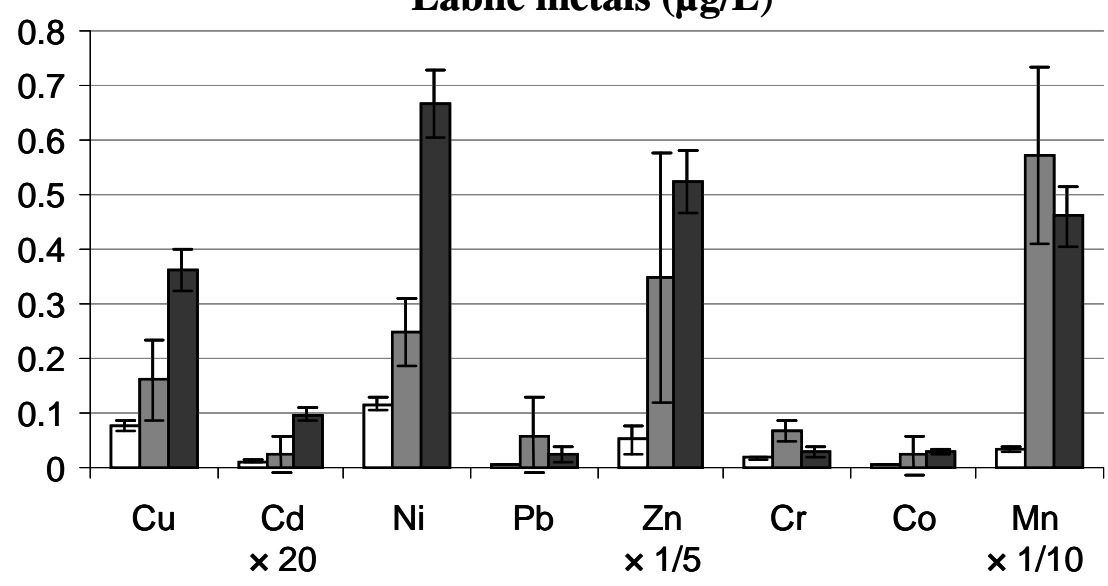


Figure 3. Histograms of normalized $\mathrm{EC}_{50}$ values (expressed as $\mathrm{mg}_{\text {metal }} / \mathrm{g}_{\mathrm{TSS}}$ ) from biofilms $\mathrm{A}$ and TA (a) and B1 and TB1 (b). Error bars represent 95\% confidence intervals.

(a)

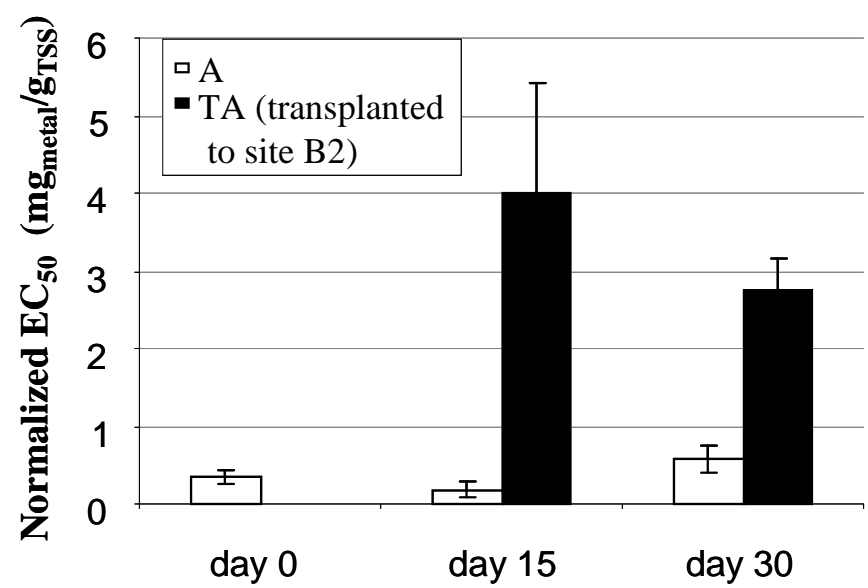

(b)

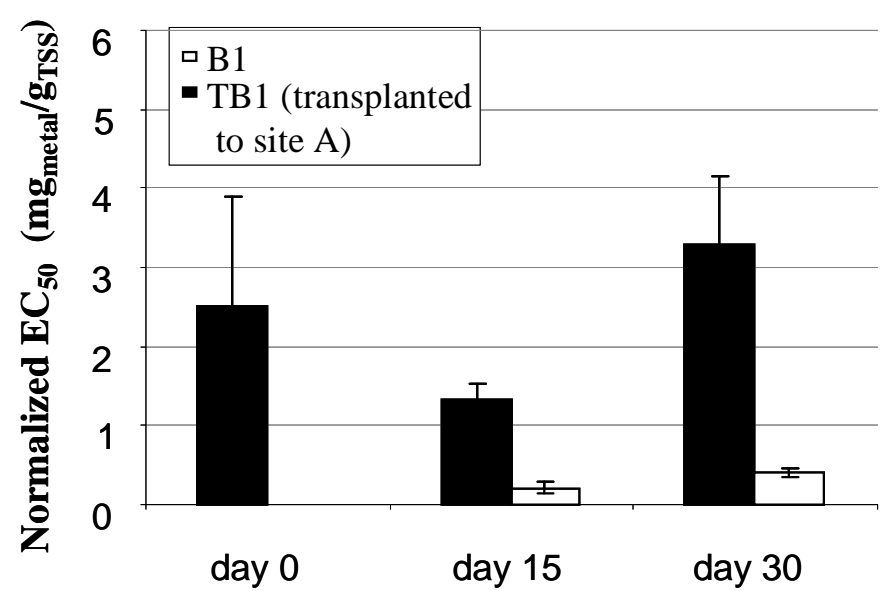


Figure 4. PLS correlation circle on the two components of the regression model $(\mathrm{t} 1 / \mathrm{t} 2)$. Observations (communities) are plotted as $\mathbf{\square}, \mathrm{Y}$ variables as $\boldsymbol{\Delta}$ and $\mathrm{X}$-variables as $\bullet$. Biofilm samples are identified by a letter corresponding to the sampling site (A or B1) or the site of origin for transplanted communities (TA and TB1) and a number corresponding to the sampling date (0 for the beginning of the experiment, 15 for day 15 and 30 for day 30). Metal concentrations are indicated by 'lab' for labile, 'tot' for total and 'dis' for dissolved metal.

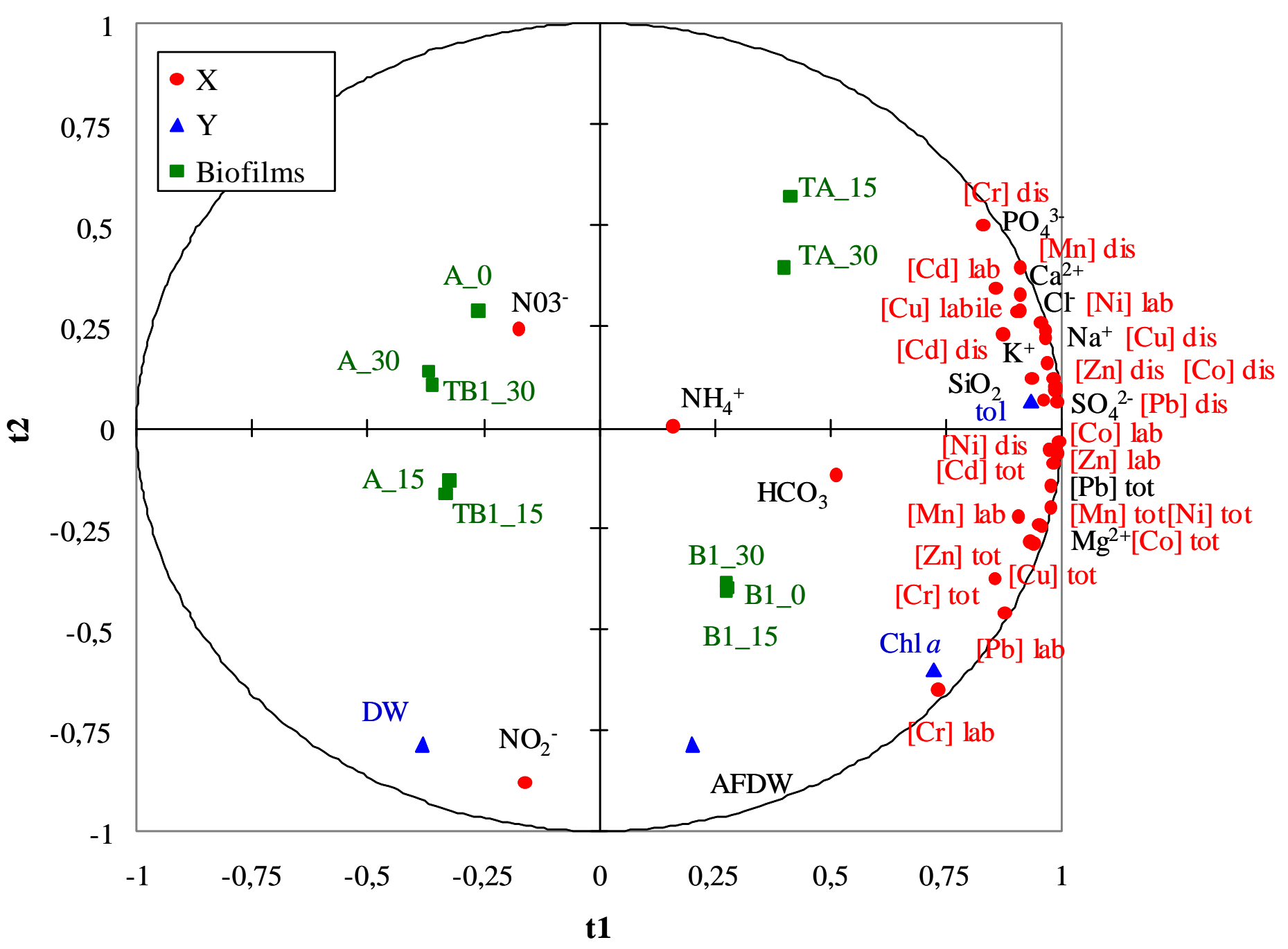


Figure 5. PCA analysis of bacterial (a) and eukaryotic (b) ARISA fingerprints of biofilm samples collected either upstream (A and TB1 communities, represented by open circles) and downstream (B and TA communities, represented by open triangles). Triplicates are grouped by ellipses. Biofilm samples are identified by a letter corresponding to the sampling site (A or B1) or the site of origin for transplanted communities (TA and TB1) and a number corresponding to the sampling date (15 for day 15 and 30 for day 30).

(a)

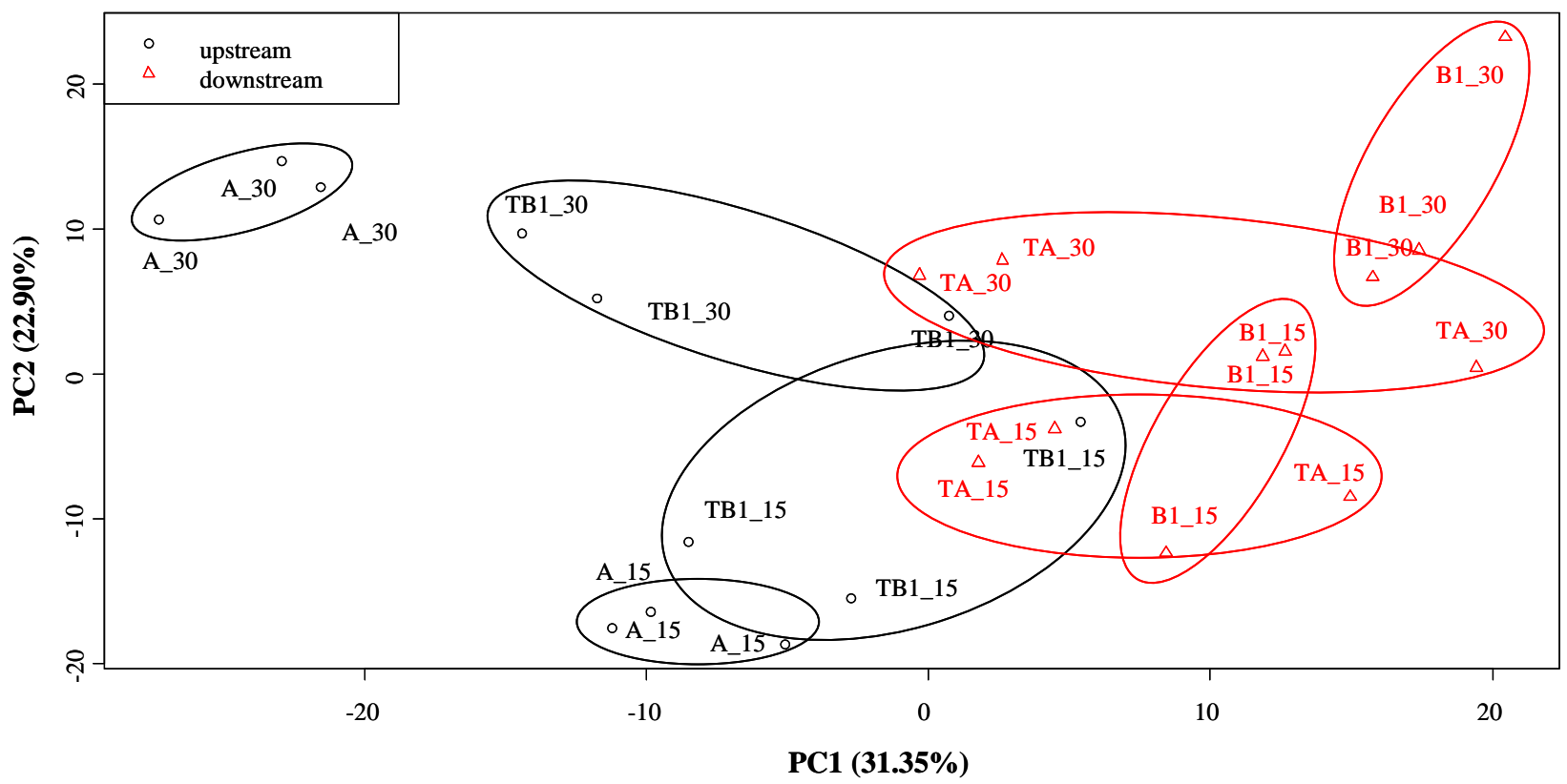

(b)

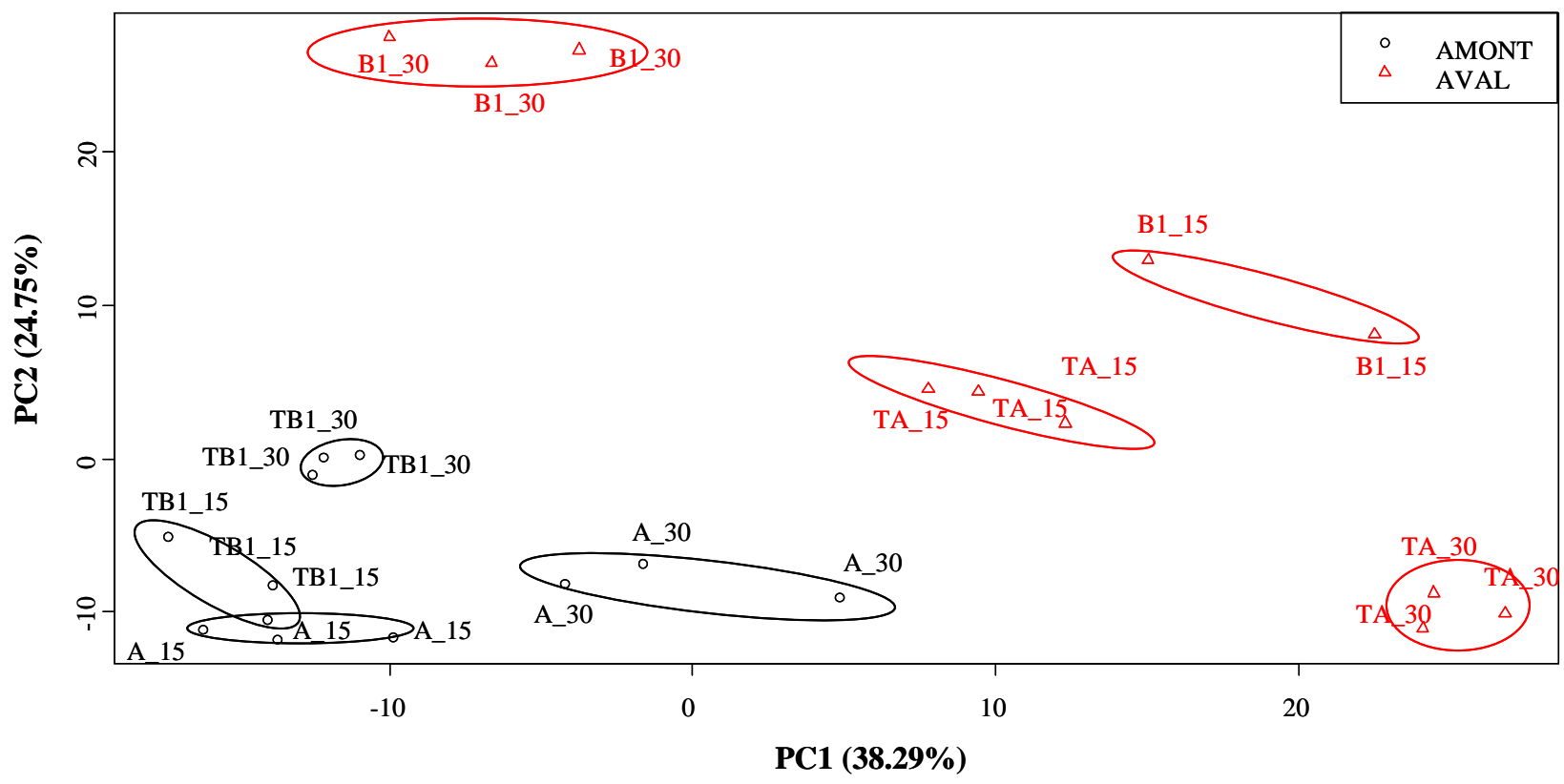


Table 1. Physico-chemical parameters of the river water at sites A, B1 and B2 on day 0, 15 and 30 (individual samplings at each date). No sampling was performed at site B1 on day 0 .

\begin{tabular}{|c|c|c|c|c|c|c|c|c|c|c|c|c|c|}
\hline site & date & $\mathbf{H C O}_{3}{ }^{-}$ & $\mathbf{N a}^{+}$ & $\mathbf{K}^{+}$ & $\mathbf{M g}^{2+}$ & $\mathbf{C a}^{2+}$ & $\mathbf{C l}$ & $\mathbf{S O}_{4}{ }^{2-}$ & $\mathbf{N}-\mathbf{N H}_{4}{ }^{+}$ & $\mathbf{N}-\mathbf{N O}_{2}{ }^{-}$ & $\mathbf{P}_{-} \mathbf{P O}_{4}{ }^{3-}$ & $\mathbf{N}-\mathbf{N O}_{3}{ }^{-}$ & $\mathbf{S i O}_{2}$ \\
\hline \multirow{3}{*}{ A } & day 0 & 201.3 & 6.27 & 1.61 & 4.48 & 73.52 & 12.08 & 14.26 & 0.01 & 0.01 & 0.15 & 2.93 & 6.45 \\
& day 15 & 170.8 & 5.68 & 1.75 & 3.98 & 66.11 & 11.51 & 14.15 & nd & 0.08 & 0.14 & 2.48 & 3.9 \\
& day 30 & 213.5 & 5.53 & 1.64 & 3.86 & 63.43 & 11.25 & 14.05 & nd & 0.03 & 0.14 & 2.23 & 3.5 \\
\hline \multirow{2}{*}{$\mathrm{B} 1$} & day15 & 225.7 & 11.61 & 3.06 & 9.90 & 81.44 & 21.69 & 36.01 & nd & 0.06 & 0.17 & 2.74 & 10.7 \\
& day 30 & 219.6 & 11.45 & 3.67 & 10.08 & 73.22 & 21.27 & 33.17 & 0.1 & 0.06 & 0.18 & 2.13 & 8.7 \\
\hline \multirow{3}{*}{$\mathrm{B} 2$} & day 0 & 176.9 & 19.79 & 4.99 & 8.19 & 88.52 & 35.92 & 45.09 & nd & 0.01 & 0.21 & 5.66 & 13.15 \\
& day 15 & 195.2 & 20.02 & 5.28 & 8.33 & 89.44 & 36.70 & 47.36 & nd & 0.01 & 0.24 & 5.88 & 12.7 \\
& day 30 & 219.6 & 20.48 & 5.36 & 8.51 & 87.16 & 38.58 & 48.07 & 0.71 & 0.02 & 0.23 & 4.62 & 10.8 \\
\hline
\end{tabular}


Table 2. Mean values and corresponding standard deviations $( \pm \sigma)$ of dry weights (DWs), ashfree dry weights (AFDWs) and chlorophyll a (Chl a) concentrations corresponding to the biofilms collected on day 0,15 and $30(\mathrm{n}=3$ for each parameter, except for DW and AFDW for samples collected on day 15 and 30).

\begin{tabular}{|c|c|ccc|}
\hline Parameter & site & Day 0 & Day 15 & Day 30 \\
\hline & A & $2.37( \pm 0.06)$ & 9,07 & 2,48 \\
DW $\left(\mathrm{mg} / \mathrm{cm}^{2}\right)$ & TA (to B2) & & 1,54 & 1,96 \\
& B1 & $4.65( \pm 0.06)$ & 6,47 & 4,49 \\
& TB1 (to A) & & 9,26 & 4,71 \\
\hline & A & $0.31( \pm 0.005)$ & 1,12 & 0,41 \\
AFDW & TA (to B2) & & 0,51 & 0,7 \\
$\left(\mathrm{mg} / \mathrm{cm}^{2}\right)$ & B1 & $1.08( \pm 0.05)$ & 1,23 & 1,41 \\
& TB1 (to A) & & 1,19 & 0,88 \\
\hline & A & $21.04( \pm 1.37)$ & $46.56( \pm 2.86)$ & $24.95( \pm 2.19)$ \\
Chl a $\left(\mathrm{mg} / \mathrm{m}^{2}\right)$ & TA (to B2) & & $56.18( \pm 3.24)$ & $65.01( \pm 10.79)$ \\
& B1 & $122.68( \pm 13.13)$ & $124.87( \pm 5.52)$ & $85.34( \pm 10.52)$ \\
& TB1 (to A) & & $56.31( \pm 4.95)$ & $36.2( \pm 1.11)$ \\
\hline
\end{tabular}


Table 3. Model fitting results of the PLS regression performed on the environmental variables describing the sampling sites $(\mathrm{X})$ and biofilm parameters $(\mathrm{Y})$ : $\mathrm{Cu}$ tolerance values from the toxicity test (tol) as well as biofilm descriptors DW, AFDW and Chl a. The number of components was restricted to two.

\begin{tabular}{|c|ccccccccccc|}
\hline $\begin{array}{c}\text { Model } \\
\text { parameters }\end{array}$ & $\mathrm{R}^{2} \mathrm{X}$ & $\mathrm{R}^{2} \mathrm{Y}$ & $\mathrm{Q}^{2}$ & $\mathrm{R}_{\text {tol }}^{2}$ & $\mathrm{Q}_{\text {tol }}^{2}$ & $\mathrm{R}_{\mathrm{DW}}^{2}$ & $\mathrm{Q}_{\mathrm{DW}}^{2}$ & $\mathrm{R}_{\text {AFDW }}^{2}$ & $\mathrm{Q}_{\text {AFDW }}^{2}$ & $\mathrm{R}_{\text {Ch a }}^{2}$ & $\mathrm{Q}_{\text {Ch a }}^{2}$ \\
\hline Component 1 & 0,79 & 0,40 & 0,25 & 0,87 & 0,84 & 0,15 & $-0,08$ & 0,04 & $-0,19$ & 0,52 & 0,41 \\
Component 2 & 0,09 & 0,40 & 0,45 & 0,00 & $-0,13$ & 0,61 & 0,52 & 0,62 & 0,41 & 0,36 & 0,54 \\
cumulated & 0,88 & 0,80 & 0,58 & 0,88 & 0,82 & 0,76 & 0,48 & 0,66 & 0,30 & 0,89 & 0,73 \\
\hline
\end{tabular}


Table 4. Variable importance (VIP > 0.8) in the two-component PLS model and corresponding regression coefficients.

\begin{tabular}{|c|c|c|c|c|c|}
\hline Variable & VIP & Coeff $_{\text {tol }}$ & Coeff $_{D W}$ & Coeff $_{\text {AFDW }}$ & Coeff $_{\text {Ch } a}$ \\
\hline $\mathrm{NO}_{2}$ & 2,891 & $-0,028$ & 0,332 & 0,332 & 0,254 \\
\hline [Cr] lab & 1,613 & 0,014 & 0,160 & 0,178 & 0,153 \\
\hline [Pb] lab & 1,326 & 0,021 & 0,115 & 0,135 & 0,123 \\
\hline$[\mathrm{Cr}] \mathrm{dis}$ & 1,178 & 0,034 & $-0,123$ & $-0,107$ & $-0,067$ \\
\hline $\mathrm{PO}_{4}$ & 1,141 & 0,036 & $-0,113$ & $-0,096$ & $-0,056$ \\
\hline $\mathrm{Ca}^{2+}$ & 0,968 & 0,033 & $-0,091$ & $-0,074$ & $-0,040$ \\
\hline [Mn] lab & 0,952 & 0,028 & 0,048 & 0,069 & 0,073 \\
\hline [Cu] tot & 0,944 & 0,027 & 0,053 & 0,073 & 0,075 \\
\hline $\mathrm{Mg}^{2+}$ & 0,930 & 0,028 & 0,046 & 0,067 & 0,071 \\
\hline [Co] tot & 0,898 & 0,027 & 0,045 & 0,065 & 0,069 \\
\hline $\mathrm{Na}^{+}$ & 0,895 & 0,035 & $-0,067$ & $-0,047$ & $-0,018$ \\
\hline $\mathrm{C}^{-}$ & 0,894 & 0,035 & $-0,068$ & $-0,049$ & $-0,019$ \\
\hline [Ni] dis & 0,894 & 0,028 & 0,040 & 0,060 & 0,066 \\
\hline [Cr] tot & 0,890 & 0,024 & 0,053 & 0,072 & 0,073 \\
\hline [Ni] tot & 0,877 & 0,028 & 0,039 & 0,059 & 0,065 \\
\hline [Zn] dis & 0,876 & 0,035 & $-0,059$ & $-0,040$ & $-0,011$ \\
\hline [Mn] dis & 0,864 & 0,033 & $-0,068$ & $-0,050$ & $-0,021$ \\
\hline [Cd] dis & 0,862 & 0,035 & $-0,057$ & $-0,038$ & $-0,010$ \\
\hline [Co] lab & 0,855 & 0,030 & 0,024 & 0,045 & 0,055 \\
\hline [Cd] lab & 0,821 & 0,032 & $-0,062$ & $-0,045$ & $-0,018$ \\
\hline [Mn] tot & 0,817 & 0,030 & 0,014 & 0,035 & 0,047 \\
\hline $\mathrm{SiO}_{2}$ & 0,803 & 0,033 & $-0,049$ & $-0,030$ & $-0,005$ \\
\hline $\mathrm{K}^{+}$ & 0,801 & 0,034 & $-0,037$ & $-0,017$ & 0,006 \\
\hline
\end{tabular}




\section{References}

Bérard, A., Benninghoff, C., 2001. Pollution-induced community tolerance (PICT) and seasonal variations in the sensitivity of phytoplankton to atrazine in nanocosms. Chemosphere 45, 427437.

Bérard, A., Dorigo, U., Humbert, J.F., Leboulanger, C., Seguin, F., 2002. La méthode PICT (Pollution-Induced Community Tolerance) appliquée aux communautés algales: intérêt comme outil de diagnose et d'évaluation du risque écotoxicologique en milieu aquatique. Annales de Limnologie 38.

Bérard, A., Pelte, T., Druart, J.-C., 1999. Seasonal variations in the sensitivity of Lake Geneva phytoplankton community structure to atrazine. Archiv Fur Hydrobiologie 145, 277-295.

Blanck, H., 2002. A Critical Review of Procedures and Approaches Used for Assessing PollutionInduced Community Tolerance (PICT) in Biotic Communities. Human and Ecological Risk Assessment 8, 1003-1034.

Blanck, H., Wängberg, S.-A., Molander, S., 1988. Pollution-Induced Community Tolerance - a new ecotoxicological tool, in: Cairns, J.J., Pratt, J.R. (Eds.), Functional Testing of Aquatic Biota for Estimating Hazards of Chemicals. American Society for Testing and Materials, Philadelphia, PA, USA, pp. 219-230.

Bouletreau, S., Garabetian, F., Sauvage, S., Sanchez-Perez, J.-M., 2006. Assessing the importance of a self-generated detachment process in river biofilm models. Freshwater Biology 51, 901-912.

Burns, A., Ryder, D.S., 2001. Potential for biofilms as biological indicators in Australian riverine systems. Ecological Management \& Restoration 2, 53-64.

Cardinale, M., Brusetti, L., Quatrini, P., Borin, S., Puglia, A.M., Rizzi, A., Zanardini, E., Sorlini, C., Corselli, C., Daffonchio, D., 2004. Comparison of Different Primer Sets for Use in Automated Ribosomal Intergenic Spacer Analysis of Complex Bacterial Communities. Appl. Environ. Microbiol. 70, 6147-6156.

Dorigo, U., Bérard, A., Bouchez, A., Rimet, F., Montuelle, B., 2010a. Transplantation of Microbenthic Algal Assemblages to Assess Structural and Functional Recovery After Diuron Exposure. Archives of Environmental Contamination and Toxicology 59, 555-563.

Dorigo, U., Bérard, A., Rimet, F., Bouchez, A., Montuelle, B., 2010b. In situ assessment of periphyton recovery in a river contaminated by pesticides. Aquatic Toxicology 98, 396-406.

Eriksson, L., Johansson, E., Kettaneh-Wold, N., Trygg, J., Wikström, C., Wold, S., 2006. Multiand Megavariate Data Analysis. Umetrics Academy, Umean, Sweden.

Fechner, L.C., Gourlay-Francé, C., Bourgeault, A., Tusseau-Vuillemin, M.H., 2011a. Metal tolerance of natural biofilms increases at Environmental Quality Standards exposure concentrations. Unpublished results.

Fechner, L.C., Gourlay-Francé, C., Tusseau-Vuillemin, M.H., 2011b. Low exposure levels of urban metals induce heterotrophic community tolerance: a microcosm validation. Ecotoxicology 20, 793-802.

Fechner, L.C., Gourlay-Francé, C., Uher, E., Tusseau-Vuillemin, M.H., 2010a. Adapting an enzymatic toxicity test to allow comparative evaluation of natural freshwater biofilms' tolerance to metals. Ecotoxicology 19, 1302-1311.

Fechner, L.C., Vincent-Hubert, F., Gaubert, P., Bouchez, T., Gourlay-Francé, C., TusseauVuillemin, M.H., 2010b. Combined eukaryotic and bacterial community fingerprinting of natural freshwater biofilms using Automated Ribosomal Intergenic Spacer Analysis. Fems Microbiology Ecology 74, 542-553.

Gold, C., Feurtet-Mazel, A., Coste, M., Boudou, A., 2002. Field transfer of periphytic diatom communities to assess short-term structural effects of metals $(\mathrm{Cd}, \mathrm{Zn})$ in rivers. Water Research 36, 3654-3664.

Gustavson, K., Wängberg, S.-A., 1995. Tolerance induction and succession in microalgae communities exposed to copper and atrazine. Aquatic Toxicology 32, 283-302. 
Harrison, J.J., Ceri, H., Turner, R.J., 2007. Multimetal resistance and tolerance in microbial biofilms. Nature Reviews Microbiology 5, 928-938.

Hill, A.V., 1910. The possible effects of the aggregation of the molecules of haemoglobin on its dissociation curves. Journal of Physiology 40, iv-vii.

Kučera, T., Horáková, H., Šonská, A., 2008. Toxic metal ions in photoautotrophic organisms. Photosynthetica 46, 481-489.

Lewis, M.A., 1992. Periphyton photosynthesis as an indicator of effluent toxicity: relationship to effects on animal test species. Aquatic Toxicology 23, 279-288.

McClellan, K., Altenburger, R., Schmitt-Jansen, M., 2008. Pollution-induced community tolerance as a measure of species interaction in toxicity assessment. Journal of Applied Ecology 45, 15141522.

Meybeck, M., 2003. Global analysis of river systems: From Earth system controls to Anthropocene syndromes. Philosophical Transactions of the Royal Society B: Biological Sciences 358, 1935-1955.

Michelland, R.J., Dejean, S., Combes, S., Fortun-Lamothe, L., Cauquil, L., 2009. StatFingerprints: a friendly graphical interface program for processing and analysis of microbial fingerprint profiles. Molecular Ecology Resources 9, 1359-1363.

Montuelle, B., Dorigo, U., Bérard, A., Volat, B., Bouchez, A., Tlili, A., Gouy, V., Pesce, S., 2010. The periphyton as a multimetric bioindicator for assessing the impact of land use on rivers: An overview of the ArdiÃ"res-Morcille experimental watershed (France). Hydrobiologia 657, 123141.

Morin, S., Pesce, S., Tlili, A., Coste, M., Montuelle, B., 2010. Recovery potential of periphytic communities in a river impacted by a vineyard watershed. Ecological Indicators 10, 419-426.

Paule, A., Lyautey, É., Garabetian, F., Rols, J.-L., 2009. Autogenic versus environmental control during development of river biofilm. Ann. Limnol. - Int. J. Lim. 45, 1-10.

Priadi, C., Bourgeault, A., Ayrault, S., Gourlay-France, C., Tusseau-Vuillemin, M.-H., Bonte, P., Mouchel, J.-M., 2011. Spatio-temporal variability of solid, total dissolved and labile metal: passive vs. discrete sampling evaluation in river metal monitoring. Journal of Environmental Monitoring 13, 1470-1479.

Ranjard, L., Poly, F., Lata, J.C., Mougel, C., Thioulouse, J., Nazaret, S., 2001. Characterization of Bacterial and Fungal Soil Communities by Automated Ribosomal Intergenic Spacer Analysis Fingerprints: Biological and Methodological Variability. Appl. Environ. Microbiol. 67, 4479-4487. Rimet, F., Cauchie, H.M., Hoffmann, L., Ector, L., 2005. Response of diatom indices to simulated water quality improvements in a river. Journal of Applied Phycology 17, 119-128.

Rotter, S., Sans-Piché, F., Streck, G., Altenburger, R., Schmitt-Jansen, M., 2011. Active biomonitoring of contamination in aquatic systems--An in situ translocation experiment applying the PICT concept. Aquatic Toxicology 101, 228-236.

Sabater, S., Guasch, H., Ricart, M., Romaní, A., Vidal, G., Klünder, C., Schmitt-Jansen, M., 2007. Monitoring the effect of chemicals on biological communities. The biofilm as an interface. Analytical and Bioanalytical Chemistry 387, 1425-1434.

Serra, A., Guasch, H., Admiraal, W., Van Der Geest, H.G., Van Beusekom, S.A.M., 2010. Influence of phosphorus on copper sensitivity of fluvial periphyton: The role of chemical, physiological and community-related factors. Ecotoxicology 19, 770-780.

Sigee, D.C., 2005. Freshwater Microbiology. Biodiversity and Dynamic Interactions of Microorganisms in the Aquatic Environment. John Wiley \& Sons, Chichester, UK.

Soldo, D., Behra, R., 2000. Long-term effects of copper on the structure of freshwater periphyton communities and their tolerance to copper, zinc, nickel and silver. Aquatic Toxicology 47, 181-189.

Tlili, A., Bérard, A., Roulier, J.L., Volat, B., Montuelle, B., 2010. $\mathrm{PO}_{4}^{3-}$ dependence of the tolerance of autotrophic and heterotrophic biofilm communities to copper and diuron. Aquatic Toxicology 98, 165-177. 
Tlili, A., Corcoll, N., Bonet, B., Morin, S., Montuelle, B., BÃ@rard, A., Guasch, H., 2011. In situ spatio-temporal changes in pollution-induced community tolerance to zinc in autotrophic and heterotrophic biofilm communities. Ecotoxicology, 1-17.

Tusseau-Vuillemin, M.-H., Gourlay, C., Lorgeoux, C., Mouchel, J.-M., Buzier, R., Gilbin, R., Seidel, J.-L., Elbaz-Poulichet, F., 2007. Dissolved and bioavailable contaminants in the Seine river basin. Science of The Total Environment 375, 244-256.

Villeneuve, A., Montuelle, B., Bouchez, A., 2009. Influence of slight differences in environmental conditions (light, hydrodynamics) on the structure and function of periphyton. Aquatic Sciences 72, 33-44.

Vindimian, E., 2001. REGTOX: The solution for dose-response modeling with Exel, p. http://www.normalesup.org/ vindimian/DOC en web/doc en 2.htm.

Vu, B., Chen, M., Crawford, R.J., Ivanova, E.P., 2009. Bacterial extracellular polysaccharides involved in biofilm formation. Molecules 14, 2535-2554. 